\title{
Correlation between ground-based observations of substorm signatures and magnetotail dynamics
}

\author{
E. Borälv ${ }^{1}$, H. J. Opgenoorth ${ }^{9,1}$, K. Kauristie ${ }^{2}$, M. Lester ${ }^{3}$, J.-M. Bosqued ${ }^{4}$, J. P. Dewhurst ${ }^{5}$, C. J. Owen ${ }^{5}$, \\ M. Dunlop ${ }^{8,6}$, J. A. Slavin ${ }^{7}$, A. Fazakerley ${ }^{5}$, and C. Perry ${ }^{8}$ \\ ${ }^{1}$ Swedish Institute of Space Physics, Uppsala, Sweden \\ ${ }^{2}$ Finnish Meteorological Institute, Space Research, Helsinki, Finland \\ ${ }^{3}$ University of Leicester, Department of Physics and Astronomy, Leicester, UK \\ ${ }^{4}$ Centre d'Etude Spatiale des Rayonnements, Toulouse, France \\ ${ }^{5}$ Mullard Space Science Laboratory, University College London, Surrey, UK \\ ${ }^{6}$ Space and Atmospheric Physics, Blackett Laboratory, Imperial College, London, UK \\ ${ }^{7}$ NASA Goddard Space Flight Center, Laboratory for Extraterrestrial Physics, Maryland, USA \\ ${ }^{8}$ Space Science Department, Rutherford Appleton Laboratory, Oxfordshire, UK \\ ${ }^{9}$ European Space Agency, ESTEC, Noordwijk, Netherlands
}

Received: 24 March 2003 - Revised: 10 January 2005 - Accepted: 13 January 2005 - Published: 30 March 2005

\begin{abstract}
We present a substorm event study using the four Cluster spacecraft in combination with ground-based instruments, in order to perform simultaneous observations in the ionosphere and magnetotail. We show good correlation between substorm signatures on the ground and in the magnetotail, even though data from the northern-ground and southern-tail hemispheres are compared. During this event ground-based magnetometers show a substorm onset over Scandinavia in the pre-midnight sector. Within $1.5 \mathrm{~h}$ the onset and three intensifications are apparent in the magnetograms. For all the substorm signatures seen on the ground, corresponding plasma sheet boundary motion is visible at Cluster, located at a downtail distance of $18.5 R_{E}$. As a result of the substorm onset and intensifications, Cluster moves in and out between the southern plasma sheet and lobe. Due to the lack of an apparent solar wind driver and the good correlation between substorm signatures on the ground, we conclude the substorm itself is the driver for these plasma sheet dynamics. We show that in the scales of Cluster interspacecraft distances $\left(\sim 0.5 R_{E}\right)$ the inferred plasma sheet motion is often directed in both $\mathrm{Y}_{g s m}$ - and $\mathrm{Z}_{g s m}$-directions, and discuss this finding in the context of previous studies of tail flapping and plasma sheet thickness variations.
\end{abstract}

Keywords. Magnetospheric physics (Magnetosphereionosphere interactions; Magnetotail; Storms and substorms)

Correspondence to: K. Kauristie

(kirsti.kauristie@fmi.fi)

\section{Introduction}

Typical substorm signatures on the ground and at the geostationary orbit are well known. The auroral brightening is considered to be the first signature of substorm onset (Liou et al., 1998). The substorm current wedge (SCW) is detected on the ground as a negative bay in the magnetic Xcomponent (Akasofu and Meng, 1969; Meng and Akasofu, 1969). At geosynchronous orbit particle injections are detected (e.g. Reeves, 1998), as well as magnetic field dipolarisations (Cummings et al., 1968). Further downtail fast tail flows and bursty bulk flows (BBFs) are observed (Angelopoulos et al., 1992). Magnetotail signatures of substorms at $19 R_{E}$ have been the subject of investigation by Geotail (e.g. Nagai et al., 1998; Miyashita et al., 1999).

There is agreement on the fact that the tail alternately thins and thickens during the substorm cycle. However, the question remains regarding the temporal and spatial development of these plasma sheet thinnings and thickenings. Earlier works on plasma sheet thinning/thickening include papers by Nishida and Fuji (1976) and Hones et al. (1984). They noted different behavior earthward and tailward of geocentric distances of $\approx 15 R_{E}$. Inside $\mathrm{r} \approx 15 R_{E}$ the plasma sheet thickens at onset, while outside $\mathrm{r} \approx 15 R_{E}$ it thins at onset and the thickening occurs during the recovery phase. More recent work on thinning/thickening has been presented by Baumjohann et al. (1992), who observed plasma sheet thinning during growth phase and thickening at onset for distances 10 $19 R_{E}$ downtail. Return to pre-growth phase plasma sheet thickness occurs roughly $45 \mathrm{~min}$ after onset, i.e. in the recovery phase. Lyons and Huang $(1992,1994)$ also found a 


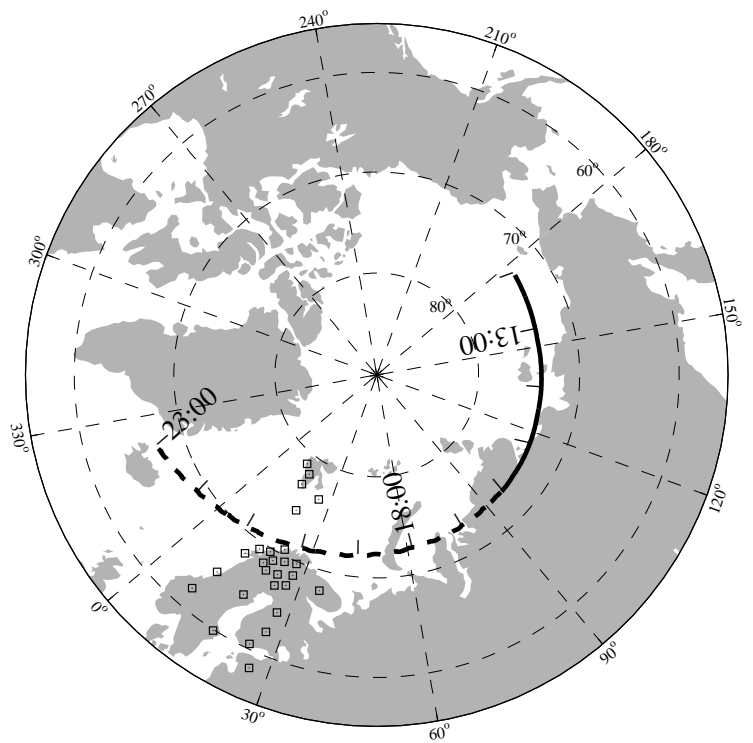

Fig. 1. Cluster footpoints on the ground, fully drawn while Cluster is above the neutral sheet, dashed while below. The IMAGE magnetometers are marked with squares. Local midnight is down in the figure at the time of substorm onset, 20:39 UT.

thickening rather than a thinning at onset, for downtail distances of $15-22 R_{E}$. They claimed that a thickening should be observed at onset for longitudes affected by the SCW, while a thinning might occur outside these longitudes.

A spacecraft initially located inside the plasma sheet suddenly can experience a "plasma sheet drop-out", as the plasma sheet disappears at the s/c position (Bame et al., 1967). In general, there are three different causes for $\mathrm{s} / \mathrm{c}$ plasma sheet drop-outs (Siscoe et al., 1994; Shodhan et al., 1996) i.e. not only associated with substorms: flapping due to solar wind interaction (windsock), intrinsic expansions and contractions (breathing), and elliptical rotation of the tail (wrenching).

New possibilities offered by the Cluster mission are based on the tetrahedron formation of the spacecraft, making it possible to separate temporal and spatial variations in the observations. The orbit apogee for nightside passes stretches out to almost $19 R_{E}$, intersecting the plasma sheet in a region which is highly active during substorms. In this paper we focus on the substorm-related dynamics of the plasma sheet. During the isolated substorm presented here, Cluster observes several plasma sheet drop-outs and returns, correlated with the substorm intensifications seen on the ground. We will present ground-based and Cluster data in order to address the cause of the plasma sheet dynamics observed during this event.

\section{Instrument description}

The substorm studied in this paper had its onset at 20:39 UT on 19 September 2001. In order to show the locations of the instruments at this moment the map in Fig. 1 is rotated such that local midnight is at the bottom center of the map

\section{IMAGE Magnetometer Network}

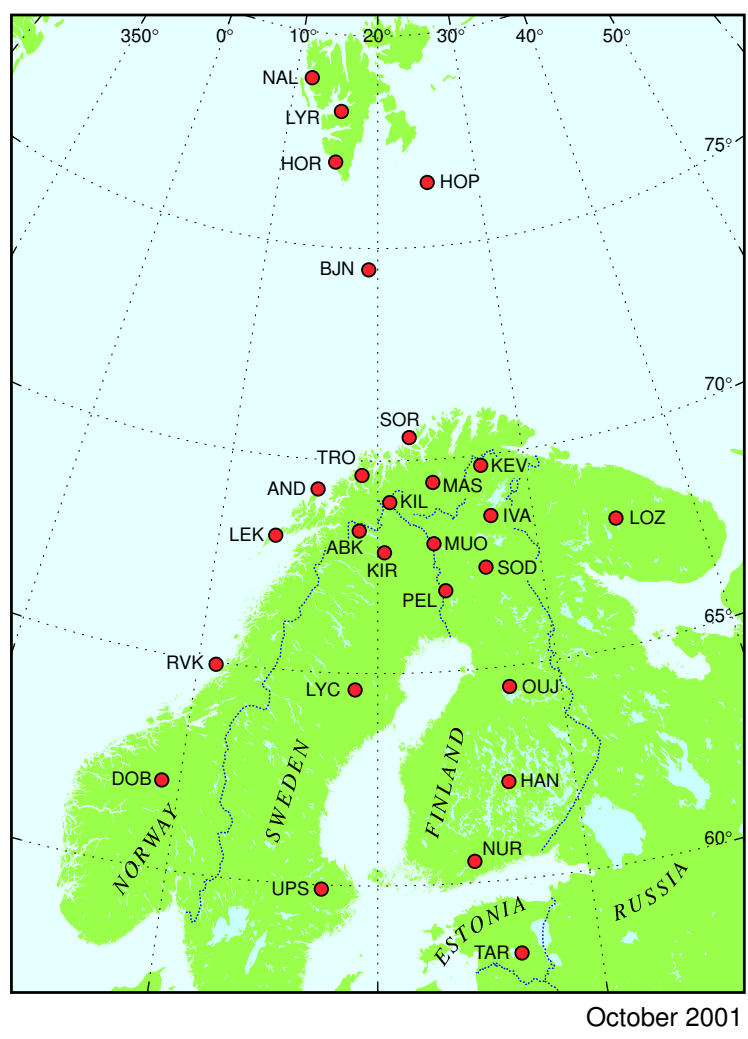

Fig. 2. Map showing the locations of IMAGE magnetometer stations, the EISCAT facility is in Troms $\varnothing$ (TRO), and the all-sky camera in Kilpisjärvi (KIL).

at the time of substorm onset. Scandinavia passes magnetic midnight around 21:30 UT and is therefore suitably located pre-midnight during this substorm. The full-drawn line in the map shows the projected footpoints of the Cluster constellation while the spacecraft are located above the neutral sheet in the tail. At $\sim 16: 00$ UT Cluster crosses the neutral sheet, and the subsequent footpoints, here mapped along field lines to the Northern Hemisphere, are shown as dashed. As can be seen, the trace of the mapped Cluster footpoints passes right over northern Scandinavia at the time of the substorm onset. The field line tracing has been done according to the empirical magnetic field model by Tsyganenko and Stern (1996). The input parameters for the model have been adjusted according to the solar wind and $D_{s t}$ conditions at the substorm onset time. The footpoint locations, especially after the neutral sheet crossing, should be intrepreted with some care, since mapping through the current sheet is likely to introduce some uncertainty. The good correlation between Cluster and ground-based observations discussed below suggests, however, that in this case the Tsyganenko model provides reasonable results.

A closer view on Scandinavia is presented in Fig. 2. The "International Monitor for Auroral Geomagnetic Effects" (IMAGE) magnetometer network (Viljanen and 

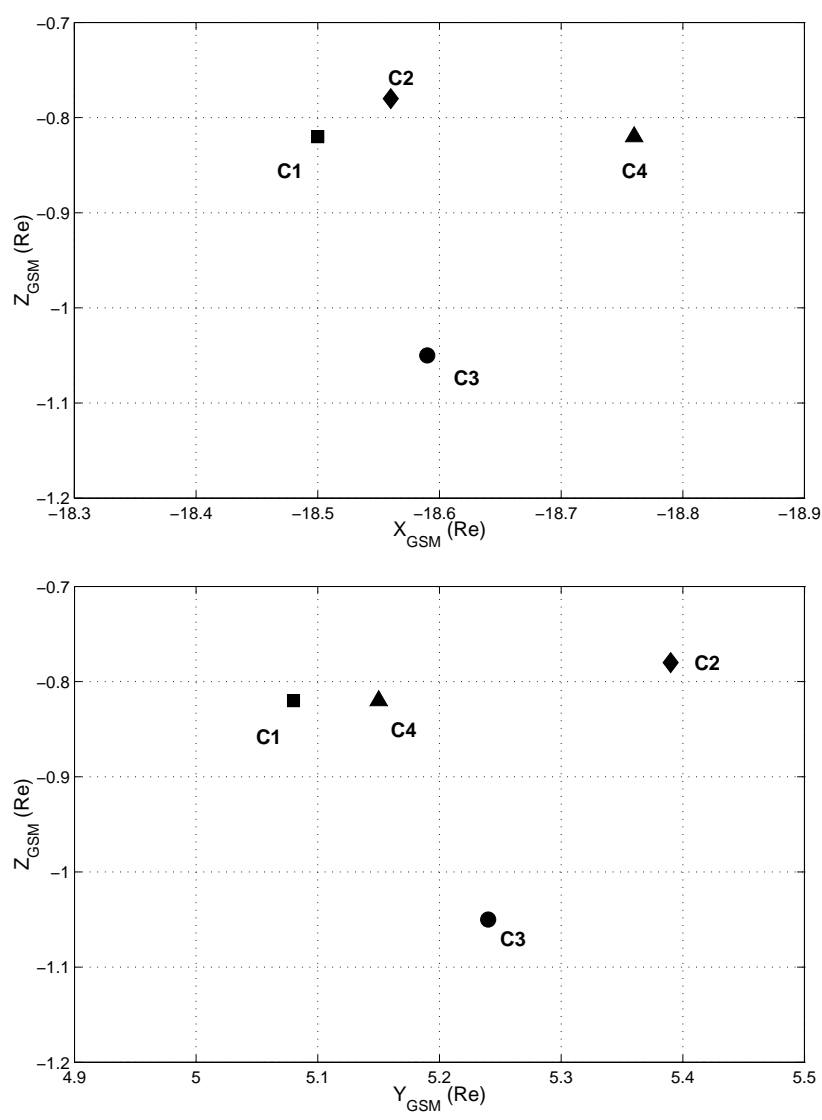

Fig. 3. The Cluster s/c relative locations at 20:39 UT.

Häkkinen, 1997) is part of a larger instrument network, the "Magnetometers-Ionospheric Radars-Allsky Cameras Large Experiment" (MIRACLE) (Syrjäsuo et al., 1998). From MIRACLE we will also employ data from an all-sky camera located in Kilpisjärvi. The "European Incoherent Scatter Radar" (EISCAT) (Rishbeth and Williams, 1985) is located in Troms $\varnothing$. During the measurements of this day the UHFbeam was pointing almost vertically.

During this substorm Cluster (Escoubet et al., 2001) was located in the tail plasma sheet at a downtail distance of $\sim 18.5 R_{E}$. Figure 3 depicts the relative locations of the Cluster spacecraft in the $\mathrm{XZ}_{g s m}$ - and $\mathrm{YZ}_{g s m}$-planes at the start of the substorm. During the nightside pass, the spacecraft constellation basically moves from smaller to larger negative $\mathrm{Z}_{g s m}$-values, i.e. away from the central plasma sheet. Note that $\mathrm{s} / \mathrm{c} 1,2$, and 4 are positioned roughly in a plane, and s/c 3 is located "below", i.e. at more negative $Z_{g s m}$. From the four Cluster spacecraft we will use data consisting of magnetic field measurements by FGM (Balogh et al., 2001), $\mathrm{H}^{+}$ ions in the range $\sim 5 \mathrm{eV} / \mathrm{e}-32 \mathrm{keV} / \mathrm{e}$ by CIS (Rème et al., 2001 ), electrons in the range $34 \mathrm{eV}-26.46 \mathrm{keV}$ detected by the HEEA sensor of the PEACE instrument (Johnstone et al., 1997), and finally high-energy electrons $(20-400 \mathrm{keV})$ by RAPID (Wilken et al., 2001).
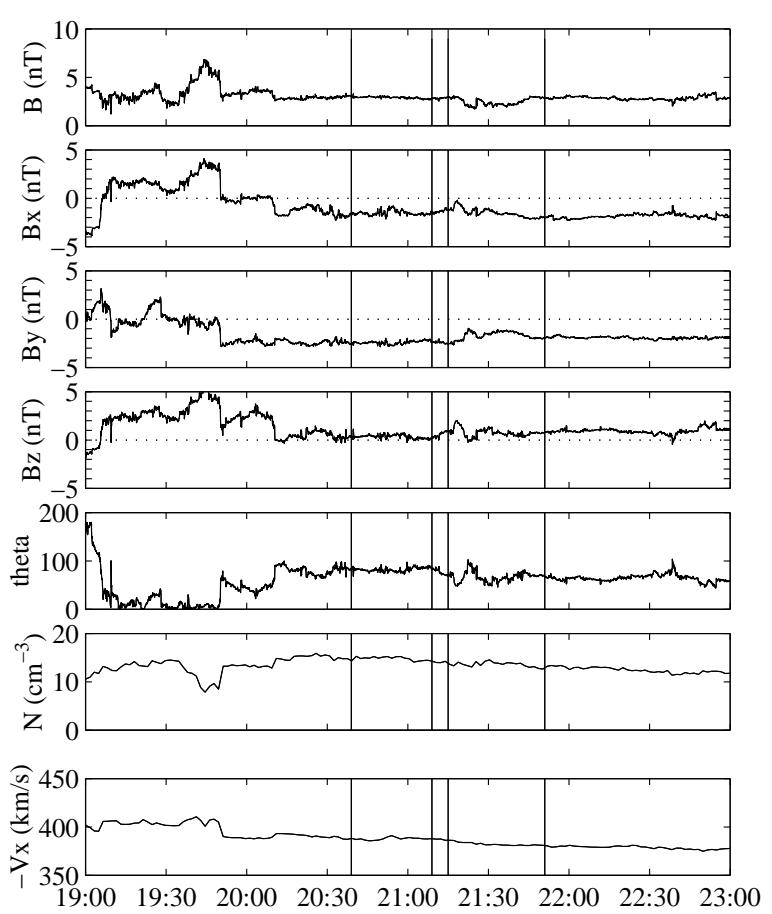

Fig. 4. Unshifted solar wind data in GSE-coordinates from WIND MFI (time resolution $3 \mathrm{~s}$ ) and SWE (time resolution $92 \mathrm{~s}$ ). The vertical lines show the times of the substorm onset and subsequent intensifications as determined from ground-based magnetic field data. The propagation time from WIND to the magnetopause was roughly 16 min.

\section{Observations}

\subsection{Solar wind observations}

Solar wind parameters for the event are shown in Fig. 4. The WIND s/c (Lepping et al., 1995; Ogilvie et al., 1995), located at $(\mathrm{X}, \mathrm{Y}, \mathrm{Z})_{g_{s e}}=(83,-44,7) R_{E}$, detected a southward turning (although not to negative $B_{z}$-values) of the interplanetary magnetic field (IMF) at $\sim 20: 11$ UT. The $B_{z}$-component remains around zero during roughly one hour, hence no considerable energy loading into the magnetosphere can be expected. The solar wind velocity is slowly decreasing from $\sim 400 \mathrm{~km} / \mathrm{s}$ (the velocities in Y- and Z-directions are negligible), giving a propagation time of roughly $16 \mathrm{~min}$ to the magnetopause, assuming the solar wind front plane to be orthogonal to the Sun-Earth line. Possibly the energy stored from previous periods of southward directed field (e.g. around 19:00 UT) eventually leads to an isolated and weak substorm at 20:39 UT.

It should be mentioned that during this day, at $\sim 18: 00$ 20:00 UT, a rotation of the IMF and an accompanying pressure pulse were detected. After that, the solar wind is more or less calm throughout the interval during which the substorm occurs. The exception is a twist visible in the clock angle after $\sim 21: 15$ UT, where the clock angle is defined similarly as in Akasofu (1980), i.e. $\theta=\arctan \left(\operatorname{abs}\left(B_{y} / B_{z}\right)\right)$. 


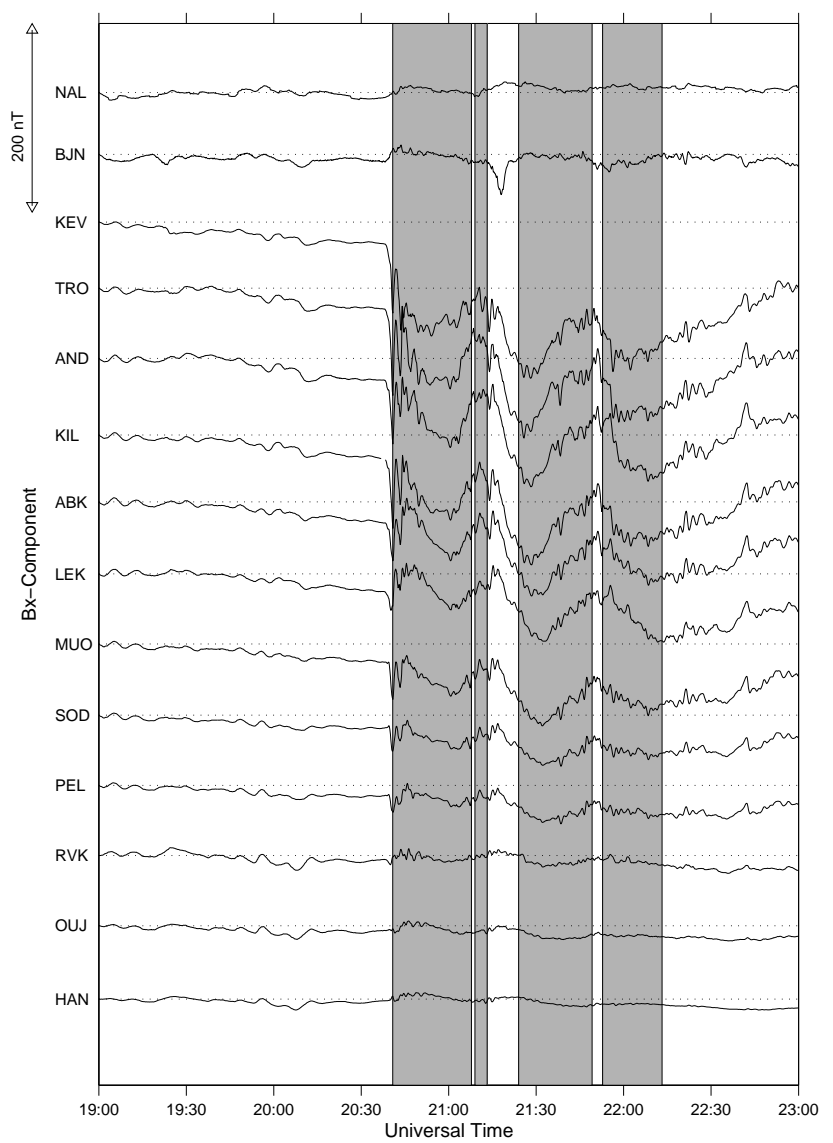

Fig. 5. Selected $B_{x}$-component magnetograms from the IMAGE network. Periods during which Cluster is in the lobe have been shaded. Note that only s/c 2 is in the plasma sheet from 21:4921:53 UT.

\subsection{Ground-based observations}

\subsubsection{Magnetic observations}

Selected 10-s resolution $B_{x}$-component magnetograms for this event are shown in Fig. 5. From these data we can distinguish several distinct substorm signatures;

- 20:39 UT Substorm onset

- 21:09 UT Substorm intensification

- 21:15 UT Substorm intensification

- 21:51 UT Substorm intensification

- 22:15 UT Start of recovery phase.

Note that with a negative bay reaching $-100 \mathrm{nT}$ this is not a particularly intense substorm. The activity caused by the Substorm Current Wedge (SCW) does not reach up to the latitudes of Svalbard (stations NAL and BJN). Nevertheless, as we will see, all of these substorm signatures have corresponding features in the Cluster data, observed below the plasma sheet. The periods when Cluster exits the plasma

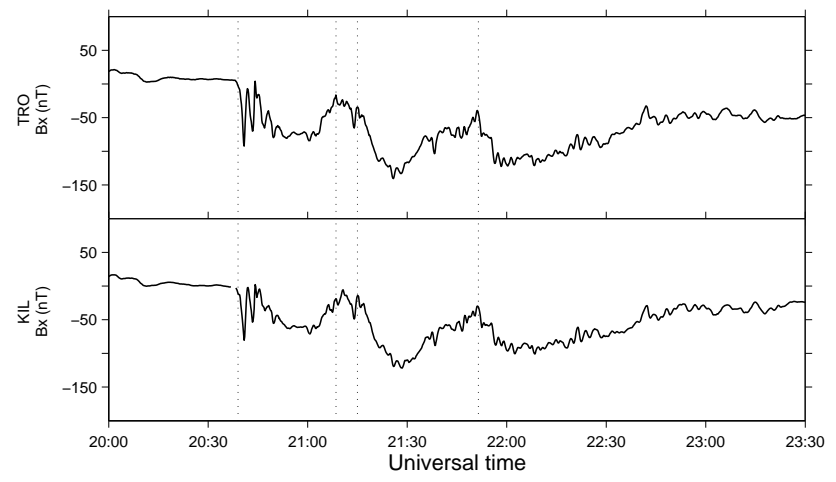

Fig. 6. $B_{x}$-component magnetograms from Troms $\emptyset$ (TRO) and Kilpisjärvi (KIL). Vertical dotted lines are marked at 20:39, 21:09, 21:15, and 21:51 UT for the onset and three intensifications of the substorm.

sheet/PSBL and is located in the southern magnetospheric lobe have been shaded in Fig. 5.

Figure 6 shows the $B_{x}$-component magnetograms from Troms $\emptyset$ and Kilpisjärvi, with vertical lines for the above determined onset and intensifications of the substorm. At these two locations we have additional data sets, from the all-sky camera (ASC) in Kilpisjärvi and EISCAT in Troms $\varnothing$, to compare both the timings of events and inspect other associated physical parameters.

\subsubsection{Optical and EISCAT observations}

The Kilpisjärvi ASC time resolution is $20 \mathrm{~s}$, and the green (5577 ̊̊) line shows an auroral brightening between 20:38:40 and 20:39:00 UT (images shown in Fig. 7). The pre-onset arc is quite faint, and the previous equatorward motion of the arc is not distinguishable. Unfortunately, the sky becomes clouded soon after the onset and so it was not possible to observe the subsequent substorm intensifications optically, but luckily the precipitation enhancements can be identified also from the EISCAT data.

One-min resolution observations by EISCAT are shown in Fig. 8. Plotted in the top panel is the electron density, and in the bottom panel the electron temperature. Clear enhancements are seen at the substorm onset at 20:39 UT. The next double-peaked intensification is not as sharply defined but still visible, at $\sim 21: 08$ and $\sim 21: 14$ UT. The last intensification is seen at $\sim 21: 48$ UT. In particular, the electron density at onset appears to initially increase at lower altitudes and propagates to higher altitudes. This is clearly an artificiality due to the beam pointing direction. The precipitating particles are expected to follow the field lines down to the ionosphere, and in a field-aligned beam pointing direction the particles would appear at the whole range of altitudes at the same instant. In this case the beam is offset from the fieldaligned position, and hence a northward moving feature, like the break-up arc in this case, would result in observations of density enhancements moving toward higher altitudes. 

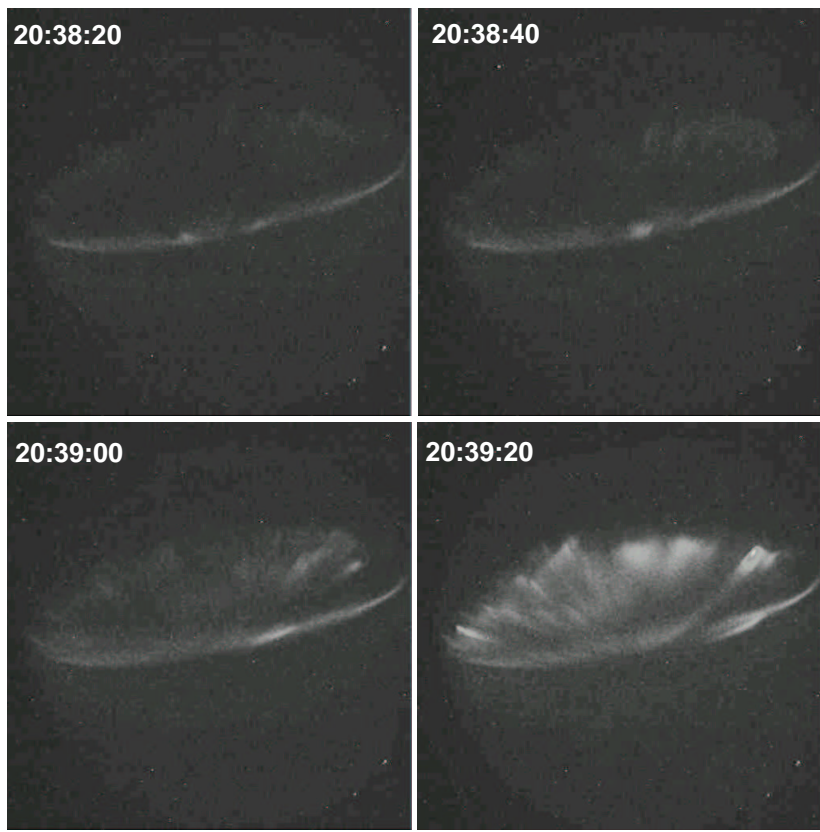

Fig. 7. Kilpisjärvi (KIL) ASC images of the green (5577 $\AA$ ) line at 20:38:20, 20:38:40, 20:39:00, and 20:39:20 UT. Images have been contrast-enhanced in order to distinguish the faint auroral arc.

\subsubsection{SuperDARN line-of-sight velocities}

The pair of CUTLASS HF-radars of the Super Dual Auroral Radar Network (SuperDARN) (Greenwald et al., 1995) monitors the ionospheric convection in the Fennoscandian sector. A selection of line-of-sight velocities recorded by the Finnish CUTLASS radar around the onset time of the substorm is shown in Fig. 9. In the plots the areas of flows toward (away from) the radar are marked with the green-blue (yellow-red) colors. The approximate location of the Cluster footpoint at $20: 38 \mathrm{UT}\left(70.68^{\circ} \mathrm{N}, 14.84^{\circ} \mathrm{E}\right)$ is shown with the black dot. During 20:38-20:42 UT the radar recorded a gradually south-east expanding region of flow with a significant equatorward component (blue region) at geographic latitudes $70-75^{\circ} \mathrm{N}$ and longitudes $0-15^{\circ}$ E, i.e. northward and slightly westward from the Cluster footpoint. Similar clearly distinct patches of Doppler velocity of between 600 $800 \mathrm{~m} / \mathrm{s}$, which at this UT is equivalent to equatorward flow appeared at the same latitudes but slightly west from the enhanced flow region at the onset for UT-periods 21:00-21:03, 21:09-21:17, and 21:28-21:48. Consequently, there was no one-to-one correspondence between the flow enhancements and the substorm intensifications as defined from the magnetometer data, although the times of the onset and the first two intensifications match with the times of the first and third flow patch observations.

In certain conditions the SuperDARN spectral width data can be used to estimate the location of the open-closed field line boundary or the boundary between field lines threading the central plasma sheet (CPS) and plasma sheet boundary layer (PSBL) (Lester et al., 2001; Chisham et al., 2004).
Typically, the region at lower latitudes with small spectral widths (SW) corresponds to closed (or CPS) field lines and the region at higher latitudes with larger SW mark the open field lines (or PSBL). The rightmost plot in the bottom row of Fig. 9 shows the spatial distribution of SW at 20:42 UT during our event (blue-green colors mark small SW and yellowred large SW). Keeping in mind that the blue area at the distant parts of the radar field-of-view should be ignored as they correspond to ground-scatter (gray areas in the other plots of the figure), one can see that there was a border between small SW and large SW approximately at $70^{\circ} \mathrm{N}$ geogr. ( $\sim 66$ MLAT). Consequently, the Cluster footpoint was in the region of PSBL field lines at that moment (which is consistent with the simultaneous ion $\beta$ measurements shown in Fig. 10) and the patches of enhanced equatorward flow built up in the polar cap region. The SW data of the SuperDARN Kerguelen radar from the Southern Hemispheric conjugate region are somewhat more sparse than the CUTLASS data but the CPS-PSBL boundary is anyway detectable from those recordings as well and the boundary appears to be roughly at the same latitudes as in the Northern Hemisphere.

\subsection{Geosynchronous observations}

Particle injections and field reconfigurations at geosynchronous orbit can provide a link between tail- and ionospheric features of substorms. During this day, however, no energetic particle injections are seen by any geosynchronous satellite. In fact, the Los Alamos National Laboratory (LANL) particle instruments (Higbie et al., 1978; Belian et al., 1992) on board s/c 1991-080, located in the ecliptic plane at a geographic longitude $7.5^{\circ}$, i.e. at Scandinavian longitudes, do not enter the nightside plasma sheet and therefore cannot provide any information on the plasma sheet. On the other hand, s/c 97-A, which is located further east of Scandinavia (geographic longitude $70^{\circ}$ ), enters the electron plasma sheet, however, not until 21:00 UT.

The likely explanation for the lack of substorm onset activity at geosynchronous orbit is that the substorm activity level is too low $(\sim 100 \mathrm{nT})$ to produce observable signatures. In such a case the inner edge of the plasma sheet does not necessarily move inside geostationary orbit. Even though the activity during this event lacks the typical substorm signature of particle injections, we will still categorize it as a substorm since the ground signatures are in agreement with a weak isolated substorm, displaying a clear onset and substorm intensifications, with a normal temporal duration.

\subsection{Tail observations}

\subsubsection{Magnetic field observations}

Figure 10 shows the magnetic field measured by Cluster. The first four panels show the magnetic components and magnitude of the field. Plotted in panel five is $B_{z} / \operatorname{sqrt}\left(B_{x}^{2}+B_{y}^{2}\right)$, i.e. the ratio of the vertical and horizontal magnetic field components. In the bottom panel the ion plasma $\beta$ has been 


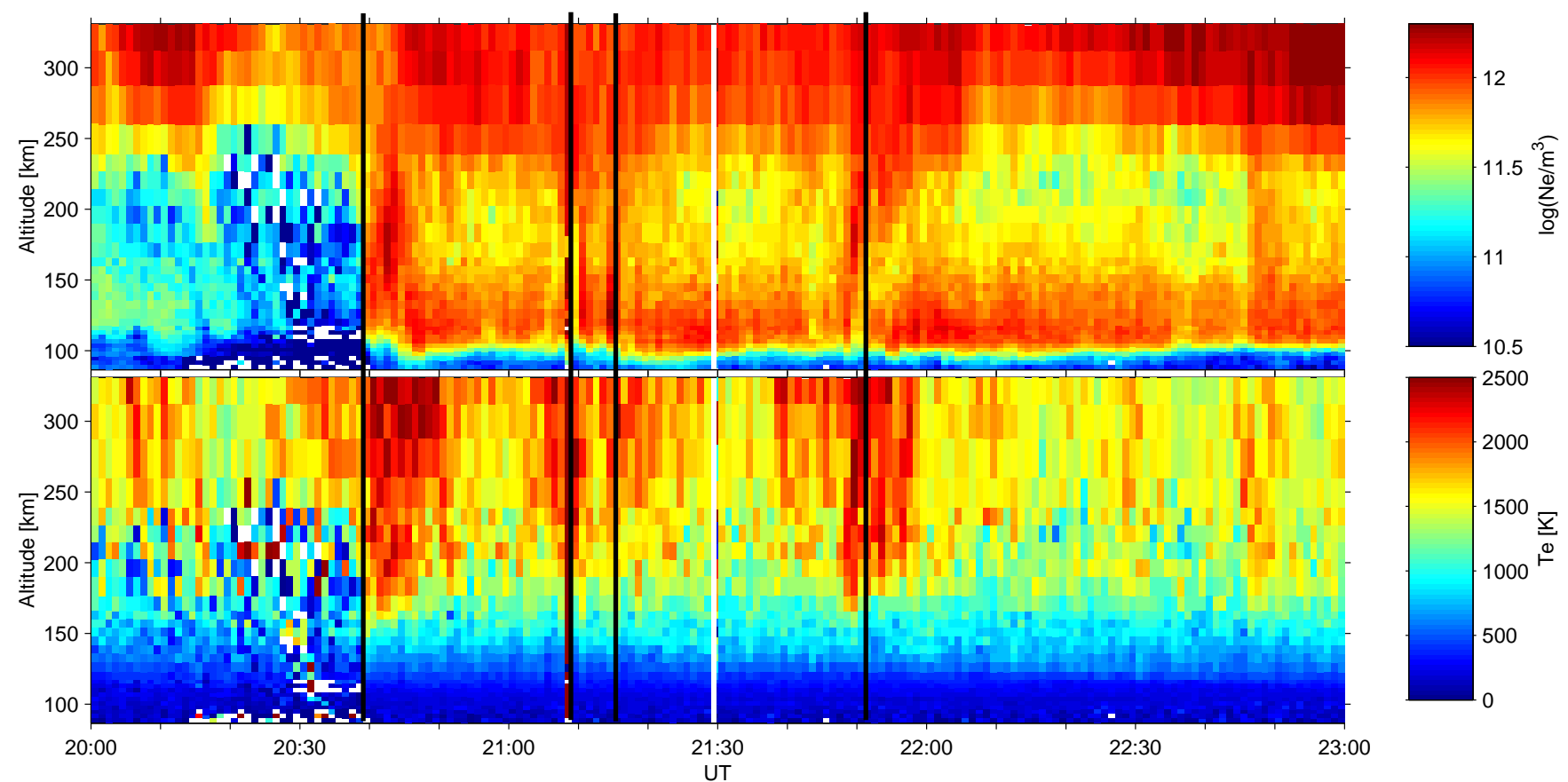

Fig. 8. One-min resolution EISCAT data of electron density and electron temperature. Substorm onset and intensifications are seen at 20:39, 21:08, 21:13, and 21:48 UT. The onset and intensification times, as determined from ground-based magnetic field data, are marked with the vertical solid lines.
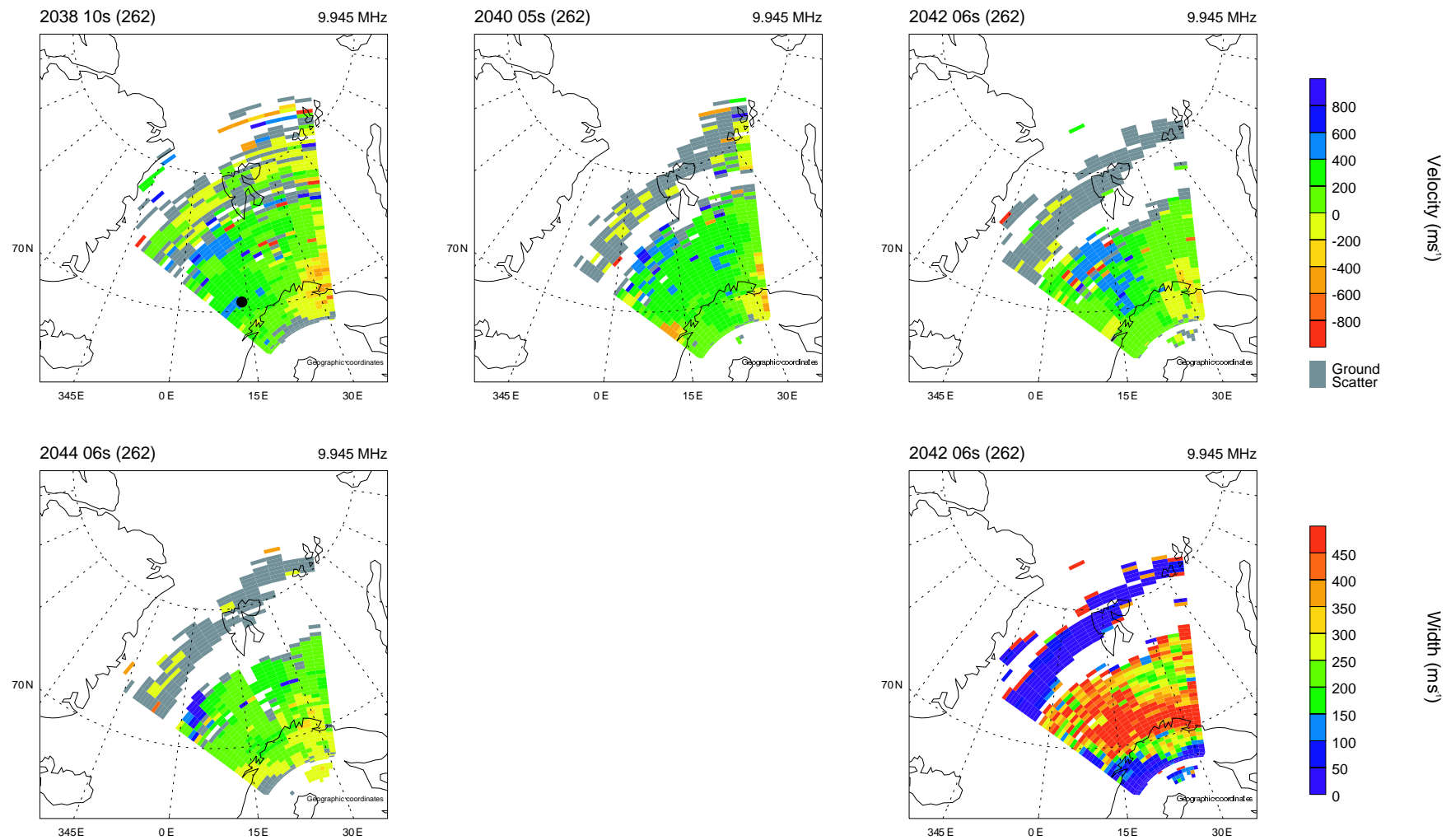

Fig. 9. Line-of-sight plasma velocities (all plots in the top row and the first plot in the bottom row) and back scatter spectral width (second plot in the bottom row) as observed by the Finnish CUTLASS radar. The green-blue (yellow-red) colors mark velocities toward (away from) the radar in the velocity plots and small (large) widths in the spectral width plots. 
calculated, utilizing additional data from the CIS instrument. Typical values of plasma $\beta$ are $\sim 30$ in the vicinity of the neutral sheet, $\sim 3$ in the inner PS and $\sim 0.3-0.4$ in the outer PS (Baumjohann et al., 1989). The four vertical dashed lines represent the timings determined from ground-based observations for the onset and intensifications of the substorm.

The first thing to note is that there is no field dipolarisation at onset. However, as the measurements are made in the PSBL and lobe regions (compare with the bottom panel), a dipolarisation could still occur in the PS without Cluster being able to observe it. The decreasing possibility of observing dipolarisations with distance from the PS has been shown in a superposed epoch analysis by Baumjohann et al. (1991). Another indication of Cluster being far from the PS is the fact that field line stretching is not visible in the magnetic field data prior to the onset.

During the main part of the substorm the magnetic field ratio is roughly constant at 0.1 , corresponding to an elevation angle of $6^{\circ}$, which is a typical value in the plasma sheet during undisturbed periods. Minor fluctuations of the field angle are observed at the plasma sheet-PSBL encounters between 21:09-21:24 UT. In this interval several traveling compression regions (TCRs) (Slavin et al., 1984) are recorded, of which two are in conjunction with major ion $\beta$ peaks, at $\sim 21: 09$ and 21:23 UT. These short-lived excursions into the plasma sheet show, however, no indications of dipolarisation of the magnetic field. This can again be explained by Cluster not penetrating deep enough into the plasma sheet. The TCR observations and their importance during this event are described further in the next section.

The major disturbances during the substorm are seen in the recovery phase after $\sim 22: 15 \mathrm{UT}$, as Cluster returns to the plasma sheet. These disturbances are mainly seen in $B_{x}, B_{y}$ and the total field strength. At 23:00 UT a strong peak of the magnetic field ratio is seen, followed by a decrease back to the initial level, with the disturbance lasting for roughly $15 \mathrm{~min}$ in total. A value of $0.4-1.2$ corresponds to an field elevation angle of $22-50^{\circ}$. Here Cluster enters the inner CPS, which makes it possible to observe the field reconfiguration.

\subsubsection{TCR observations}

Recently, this same substorm interval has been analyzed independently by Slavin et al. (2003c) due to the presence of TCRs in the FGM magnetometer measurements. TCRs are compressions of the lobe magnetic field caused by localized bulges in the plasma sheet that move quickly in the earthward or tailward direction. As diagrammed in Fig. 11, the magnetic field caught between the bulging of the plasma sheet and the nearly stationary magnetopause (Slavin et al., 1993) is compressed and constrained to drape closely about the plasma sheet bulge. When such bulges in the plasma sheet propagate rapidly earthward or tailward, the result is a region of compression in the lobe that "travels" with the plasma sheet bulge; hence, the term "traveling compression region".

TCRs have been studied and utilized extensively in the deep magnetotail $\left(\mathrm{X} \lesssim-30 R_{E}\right)$ to remotely sense the motion

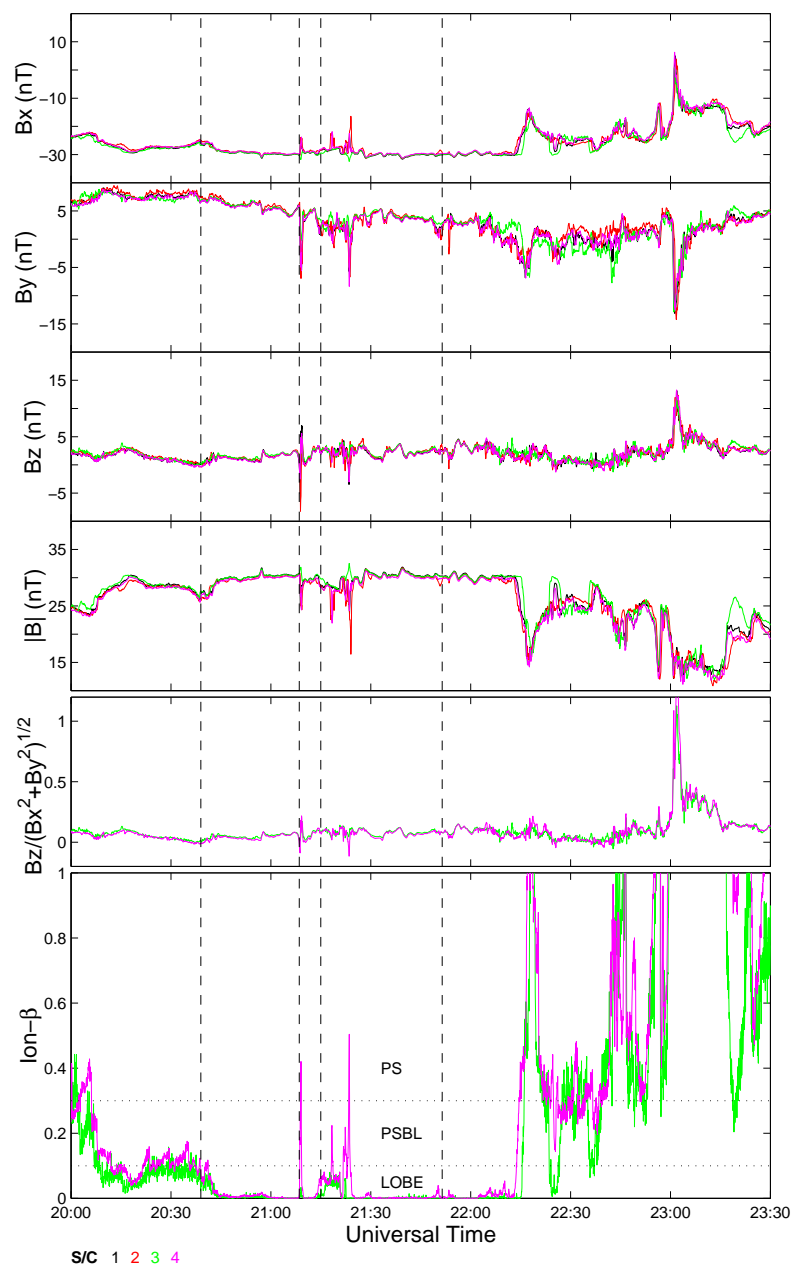

Fig. 10. First four panels show magnetic field data from Cluster. Panel five shows the ratio of the vertical and horizontal magnetic field components. Bottom panel shows ion beta value calculated with ion data from s/c 3 and 4. Typical values of the lobe, PSBL, and plasma sheet regions are indicated with the dotted horizontal lines.

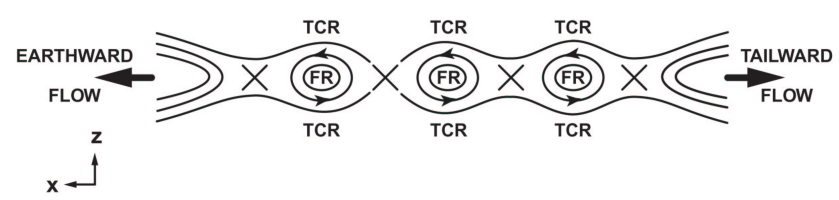

Fig. 11. Simultaneous reconnection at N+1 X-lines will convert the closed magnetic fields in the thinned plasma sheet into $\mathrm{N}$ flux ropes, plus some newly created closed (left-hand side of figure) and interplanetary (right-hand side) flux tubes. Flux ropes sunward of the NENL will be carried earthward as BBF-type events and those anti-sunward will be swept tailward as plasmoid-type flux ropes. Figure from Slavin et al. (2003c)

and dimension of plasmoid-type flux ropes as they rapidly move tailward at speeds of 500 to $1000 \mathrm{~km} / \mathrm{s}$ (Slavin et al., 1984, 1993; Taguchi et al., 1998). More recently, small flux ropes with diameters of $\sim 1-2 R_{E}$ have been found to 


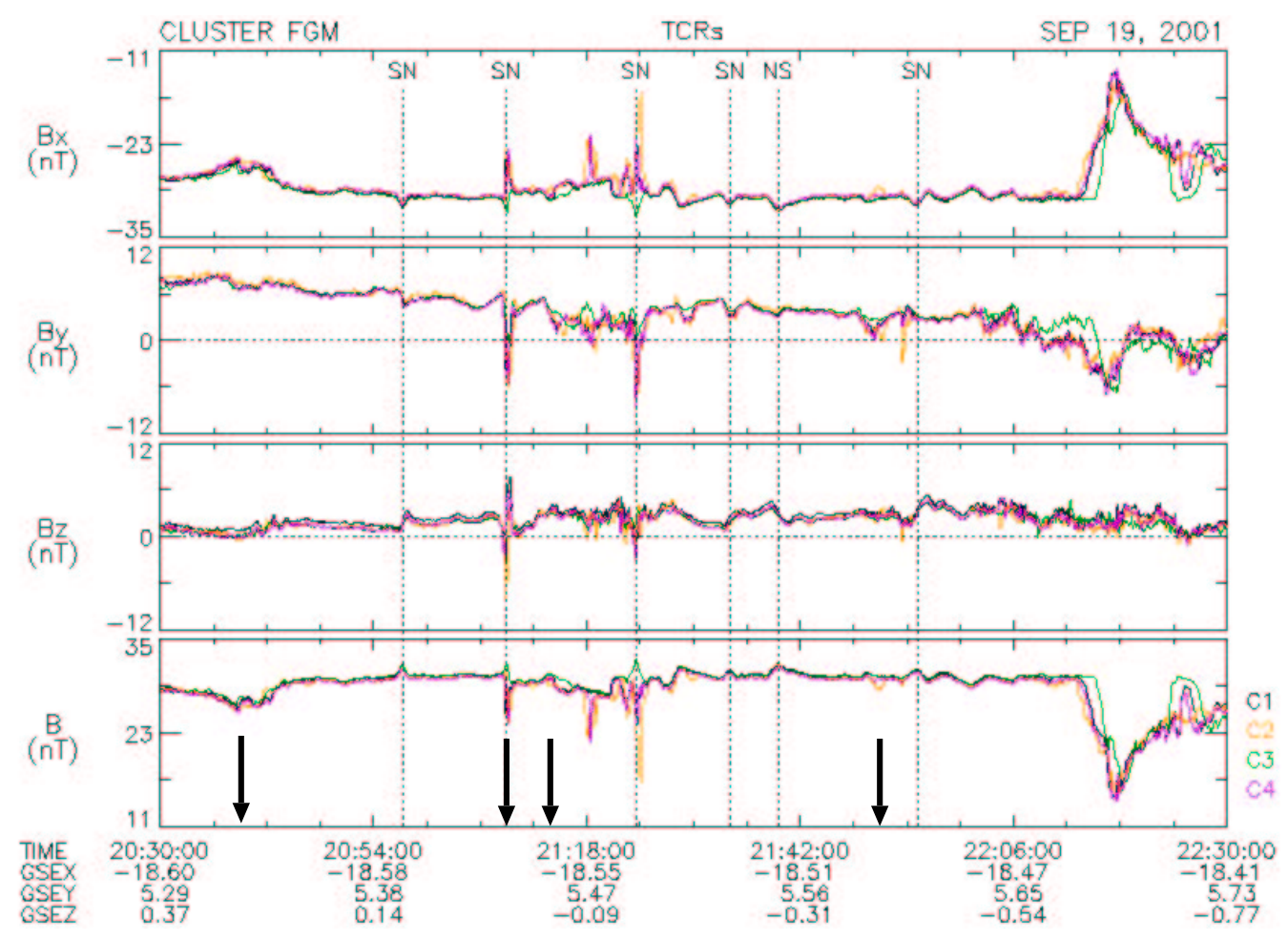

Fig. 12. FGM magnetic field data with vertical dashed lines pointing out the occurrence of TCRs. SN TCRs are observed at 20:57:20, 21:08:58, 21:23:32, 21:34:06, and 21:55:10 UT, and a single NS TCR occurs at 21:39:35 UT. The substorm onset and intensification times as determined from ground-based magnetic field data are marked with the black arrows in the bottom panel.

be common in the near-tail plasma sheet at distances of $\mathrm{X} \gtrsim-30 R_{E}$ (Slavin et al., 2003a,b). These studies found that earthward of $\mathrm{X} \sim-25 R_{E}$, the mean location of the nearEarth neutral line (NENL) (Nagai et al., 1998), the plasma sheet flux ropes are generally immersed within earthward directed bursty bulk flows. They are referred to as "BBF-type" flux ropes in contrast with the "plasmoid-type" seen predominantly beyond that distance.

Figure 12 provides an overview of the FGM magnetic field measurements with the locations of the TCRs identified by Slavin et al. (2003c) indicated with vertical dashed lines. The individual TCRs are marked as being "SN" or "NS", depending upon the sense of the $B_{z}$ variation; south-then-north (SN) associated with earthward moving plasma sheet bulges and north-then-south (NS) for the tailward moving compressions. As shown in Fig. 11, the SN TCRs should indicate that the Cluster spacecraft was earthward of the NENL while the observation of an NS TCR suggests that a NENL had formed between the Earth and the spacecraft. In the case of this substorm, 5 of the 6 TCRs are of the SN type and, therefore, should correspond to earthward moving plasma sheet bulges, probably due to BBF-type flux ropes. The single NS TCR is presumably associated with a NENL forming earthward of the Cluster spacecraft.

What do these TCR observations contribute to our understanding of this substorm? First and foremost the TCRs strongly suggest that multiple $\mathrm{X}$-lines were active during the substorm, which according to the statistical study by Slavin et al. (2005) is quite common. In our case the TCR activity further implies that reconnection continued until at least 21:55 UT. The first TCR observation at 20:57 UT is $\sim 17 \mathrm{~min}$ after the onset of the substorm. Unfortunately, the Cluster lobe measurements do not tell us whether or not this onset was determined by a NENL driven high-speed earthward flow; only that if there was such a flow, then it did not carry with it any flux ropes that caused the thinned plasma sheet to bulge. The 21:09 UT TCR was indeed nearly coincident with a substorm intensification, but the next three TCRs did not have a clear correlation with any ground-based substorm signatures. The last TCR at 21:55 UT was observed just a few minutes following the final intensification of the substorm and no TCRs were detected during the recovery phase. These observations are consistent with the findings of previous TCR and flux rope studies: TCRs and ionospheric substorm intensifications are both closely related to the NENL dynamics and thus, their temporal appearance can be similar, although all TCRs do not necessarily have any direct ionospheric signatures. The localized plasma sheet bulge that is TCR's counterpart in the closed field lines has either no magnetic connection with the ionosphere, such as in the idealized two dimensional picture of Fig. 11, or in a more realistic situation it appears as a magnetic flux rope that may or may not have footpoints in the ionosphere. 


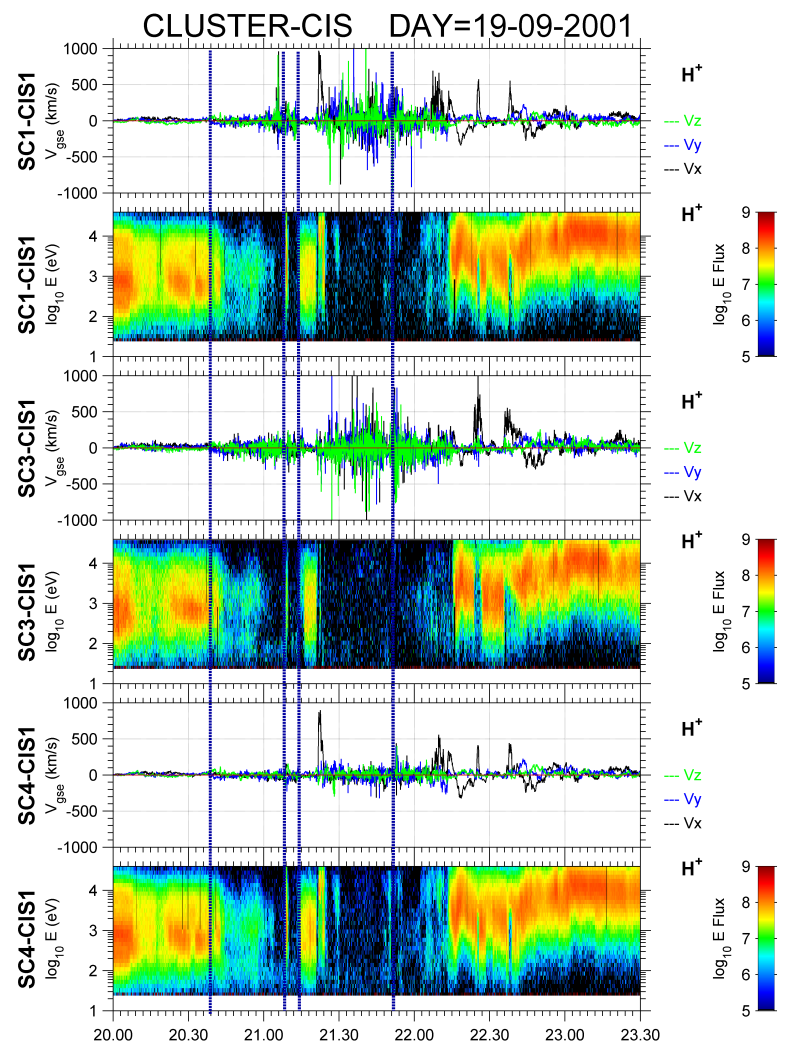

Fig. 13. $\mathrm{H}^{+}$ion velocities (GSE components) and energy flux-time spectrograms, measured by the CIS1/CODIF instruments on s/c 1 , 3 , and 4. Vertical dashed lines mark the substorm onset and intensifications as determined from the ground-based magnetic field data. Energy fluxes are integrated over $4 \pi$ steradians and the time resolution is $8 \mathrm{~s}$. Moments have been derived with a 4-s resolution. In the lobes, where the ion density is lower than $\sim 0.05 \mathrm{~cm}^{-3}$, velocity components are meaningless.

\subsubsection{Ion observations}

$\mathrm{H}^{+}$ion measurements by the CIS1/CODIF instrument on board s/c 1, 3, and 4 are shown in Fig. 13 (during this period CIS was not operational in s/c 2). The line plots show the ion velocities in GSE coordinates (the 1st, 3rd, and 5th panel) computed as moments from the spectrogram data (the 2nd, 4th, and 6th panel). The high velocity variations observed within the tenuous $\left(\mathrm{N}<0.1 \mathrm{~cm}^{-3}\right)$ lobe plasma should be considered with some reservation. The energy time spectrograms show the omni-directional energy fluxes integrated over $4 \pi$ steradians. The first interesting feature to notice in the spectrograms is the correlation between the substorm onset and intensifications as detected on the ground (pointed out in the figure by vertical dashed lines) and at Cluster. Soon after the auroral breakup, the spacecraft drop out from the plasma sheet into the lobe. At the 21:09 and 21:15 UT intensifications brief intervals of plasma sheet and its boundary layer reentries are seen in the tail. The last intensification at 21:51 UT is not visible here, however, it turns out from other data (see below) that only s/c 2 is in position to properly detect plasma sheet populations.

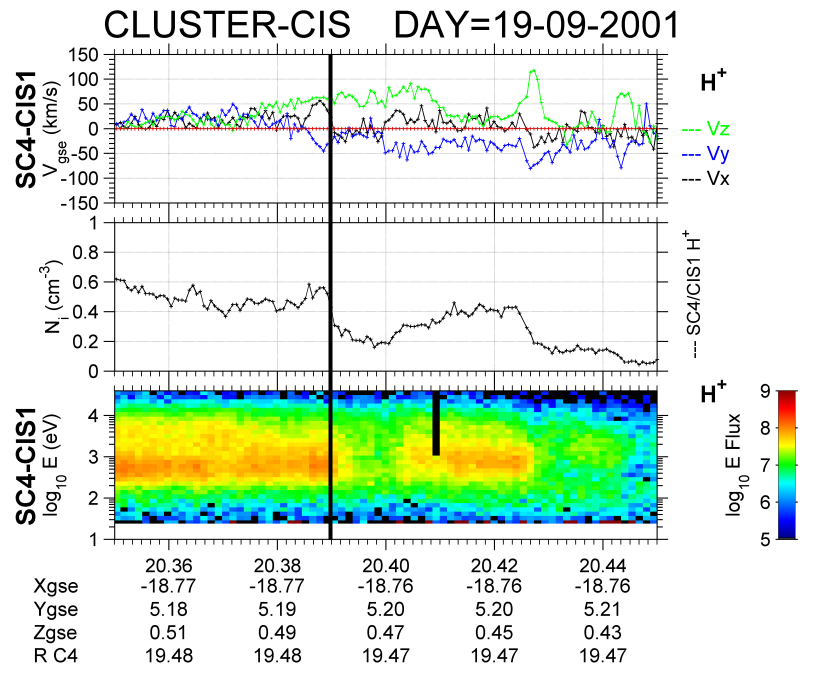

Fig. 14. $\mathrm{H}^{+}$ion velocity components, $\mathrm{H}^{+}$density and energy-time spectrogram, measured by CIS on s/c 4 . The black arrow in the bottom panel marks the onset time as determined from ground-based magnetic field data.

Figure 14 shows the CIS-recordings (5th and 6th panels from Fig. 13 and $\mathrm{H}^{+}$ion density data) for a shorter time period around the onset moment. This plot shows that the spacecraft dropout did not occur as a single step. There was a slight decrease in the ion density between $\sim 20: 39-20: 40$ UT, i.e. around the onset time as deduced from ground-based observations. However, this decrease recovered and the proper exit to lobe took place later, at 20:42 UT. The initial decrease is most likely the first signature of the onset at Cluster. It can be mentioned that at this moment the Polar s/c (Russell et al., 1995), located at $(\mathrm{X}, \mathrm{Y}, \mathrm{Z})_{g_{s m}}=(-8.97,-1.57,2.75) R_{E}$, observed gradient changes in $B_{y}$ - and $B_{z}$-components (not shown), corroborating the timing of the magnetospheric substorm onset at the first density decrease at Cluster.

We also note the lack of any substorm precursors, such as fast flows and BBFs at Cluster. The lack of BBFs can be explained by the location of the spacecraft relative to the central plasma sheet. According to Baumjohann et al. (1990), BBFs are mainly seen in $\mathrm{Y}_{g s m} \leq \pm 5 R_{E}$, and with increasing occurrence rate further tailward (measurements were made to $\sim 19 R_{E}$ downtail in their statistical study).

Between 21:21-21:24 UT, i.e. at the time of the third TCR, s/c 1 and 4 encounter the plasma sheet or PSBL identified by high-velocity, $600-800 \mathrm{~m} / \mathrm{s}$, earthward-directed beams. These two s/c are located at the smallest Y-values in the configuration. Also, according to ion measurements, s/c 3 does not properly enter the plasma sheet at this occasion.

In the recovery phase, as the $\mathrm{s} / \mathrm{c}$ enter the PSBL, several alternating earthward and tailward ion beams are seen, with velocities of the order of $\pm 200 \mathrm{~km} / \mathrm{s}$. These beams are not seen after 23:00 UT, when the s/c are back in the plasma sheet proper. 
Table 1. Observations by PEACE. In the first column "out" refers to s/c motion out from the plasma sheet, and "in" a return into the plasma sheet.

\begin{tabular}{llllllc}
\hline & $\begin{array}{l}\text { Time s/c } 1 \\
\text { (UT) }\end{array}$ & $\begin{array}{l}\text { Time s/c 2 } \\
(\mathrm{UT})\end{array}$ & $\begin{array}{l}\text { Time s/c } 3 \\
(\mathrm{UT})\end{array}$ & $\begin{array}{l}\text { Time s/c } 4 \\
(\mathrm{UT})\end{array}$ & $\begin{array}{l}\text { Boundary normal GSM } \\
(\mathrm{X}, \mathrm{Y}, \mathrm{Z})\end{array}$ & $\begin{array}{c}\text { Boundary velocity } \\
(\mathrm{km} / \mathrm{s})\end{array}$ \\
\hline out & $20: 42: 42$ & $20: 41: 35$ & $20: 42: 02$ & $20: 42: 38$ & $(-0.18,-0.93,0.30)$ & 32 \\
in & $21: 08: 42$ & $21: 08: 49$ & $21: 08: 59$ & $21: 08: 39$ & $(0.28,0.47,-0.84)$ & 95 \\
out & $21: 09: 31$ & $21: 09: 29$ & $21: 09: 15$ & $21: 09: 20$ & $(0.65,-0.09,0.75)$ & 99 \\
in & $21: 14: 18$ & $21: 13: 30$ & $21: 16: 10$ & $21: 14: 14$ & $(-0.05,-0.14,-1.00)$ & 12 \\
out & $21: 20: 48$ & $21: 21: 38$ & $21: 20: 54$ & $21: 20: 51$ & $(0.19,0.89,0.41)$ & 36 \\
in & $21: 21: 36$ & $21: 22: 07$ & $21: 22: 19$ & $21: 21: 44$ & $(-0.04,0.71,-0.70)$ & 41 \\
out & $21: 24: 22$ & $21: 24: 43$ & $21: 22: 41$ & $21: 24: 16$ & $(0.09,0.00,1.00)$ & 14 \\
in & - & $21: 49: 41$ & - & - & - & - \\
out & - & $21: 53: 47$ & - & - & - & $(-0.07,0.07,-0.99)$ \\
in & $22: 13: 26$ & $22: 13: 04$ & $22: 15: 25$ & $22: 13: 20$ & & 12 \\
\hline
\end{tabular}

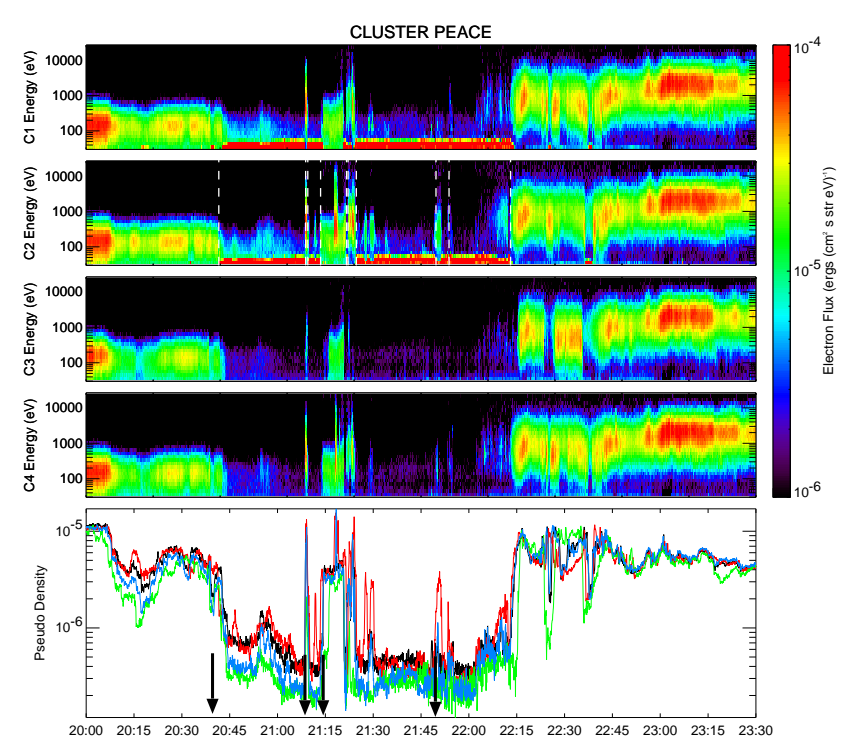

Fig. 15. Electron energy spectrograms, measured by PEACE on all four $\mathrm{s} / \mathrm{c}$ and (bottom) the partial electron density (for the exact definition see text). Vertical dashed lines in the second panel mark the plasma sheet boundary crossing times (cf. Table 1). The substorm onset and intensification times as determined from the ground-based magnetic field data are marked with the black arrows in the bottom panel.

\subsubsection{Electron observations}

PEACE observations of electrons are shown in Fig. 15. The electron spectrograms support the same temporal and spatial variations as the ion observations, however, from the electron measurements we can also derive the motion of the plasma sheet boundary crossing Cluster. Such a transition manifests itself as a sharp change in the properties of the electron populations observed by the PEACE instrument, generally from a hot, relatively dense plasma sheet population to a cold and tenuous lobe population. The relative timings of these changes in the electron populations at each of the four spacecraft can therefore be used to determine the speed of this boundary, and the local normal to this surface, as it passes over the known location of each spacecraft (e.g. Harvey, 1998; Owen et al., 2001). In order to consistently identify the correct time-lags between the observation of the boundary at each pair of spacecraft, we employ a stepped correlation technique using a "partial" electron density moment, derived from the pitch angle distribution data. Due to the low plasma densities generally found in the lobes of the magnetotail, the spacecraft potential may rise to several tens of volts if not controlled by the ASPOC instrument (e.g. Torkar et al., 2001), such that photoelectrons of spacecraft origin appear in the HEEA energy range. The partial density moment (shown in the bottom panel of Fig. 15) is obtained by integrating over the HEEA energy ranges that extend from above those of the photoelectron population during a given event. Although this "partial" density cannot be considered to represent an accurate plasma density, the temporal variations in this product are sufficient to determine the times of the boundary crossing at each of the four spacecraft and thus the motion and orientation of this boundary.

The timings of the boundary crossings are shown in Table 1 and with the white dashed lines in Fig. 15. It should be pointed out that these are the main but not all of the PSPSBL or lobe encounters observed, for example, s/c 2 moves twice in and out of the plasma sheet between 21:49:41 and 21:53:47 UT.

At the initial substorm onset the plasma sheet boundary is moving in the direction of the normal, $n=(-0.18,-0.93$, $0.30)$, i.e. the boundary is moving mainly in the negative Ydirection. The same feature is seen especially at the s/c 2 boundary crossing at 21:21:38 UT. This means that in some cases the processes of the plasma sheet thinning/thickening, or alternatively plasma sheet motion (flapping), seems to be important in Y- as well as in the Z-direction. 
The fastest boundary velocity associated with the first substorm intensification, observed by the four spacecraft between 21:08-21:09 UT, is associated with the passage of the second TCR. For other crossings the boundary velocities are not as large, not even at the substorm onset.

Boundary motion at 21:50 UT associated with the last intensification is seen only by s/c 2 , such that a normal and velocity cannot be determined. The last intensification is weak according to ground-based magnetometers, and presumably the plasma sheet does not move far enough to be seen by all s/c. Finally, the return to the plasma sheet later on, at $\sim 22: 15 \mathrm{UT}$, is a result of the plasma sheet thickening and/or moving mainly in the negative Z-direction.

RAPID measured the high-energy electron fluxes during the event (data not shown here). In these data the onset is not observable due to the lack of energetic electrons prior to the substorm. The intensification at 21:09 UT, however, shows an increase in electron counting rates for all s/c apart from number 3. Similarly, all the s/c show increased electron levels at the intensification at 21:15 UT. At 21:51 UT mainly s/c 2 records an observable increase. During the recovery phase high electron levels are detected around $\sim 23: 00 \mathrm{UT}$, as the s/c return to the plasma sheet.

\section{Summary of observations}

In the substorm event described above we have shown good correspondence between substorm signatures seen on the ground and at Cluster orbit, even if data from the northernground and southern-tail hemispheres are compared. Worth noting is that this substorm is not particularly intense, yet still we see a clear correspondence in the observations from the ground and at Cluster in the mid-tail. The lack of substorm signatures at geostationary orbit can be explained by the substorm not being strong enough to produce all classical signatures, as the inner edge of the plasma sheet does not move inside geostationary orbit.

The correspondence between the substorm signatures as observed at the ground and by Cluster can be summarised as follows:

Substorm onset

- Ground: An abrupt, negative deviation in $B_{x}$ and an auroral breakup at 20:39 UT; EISCAT recorded an enhancement in the precipitation at 20:38 UT; CUTLASS recorded enhanced equatorward flows in the polar cap during 20:38-20:42 UT;

- Cluster: FGM\&CIS showed a gradual decrease in ion $\beta$ around 20:39 UT; exit from PS at 20:39 and 20:42 UT observed by CIS; PEACE recorded a PS dropout at 20:42 UT;

1st substorm intensification

- Ground: A new, short, negative deviation in $B_{x}$ at 21:09 UT; enhanced precipitation as observed by EISCAT at 21:08 UT; CUTLASS recorded enhanced equatorward flows in the polar cap during 21:09-21:17 UT;
- Cluster: Signatures of a TCR passage (2nd in Fig. 12), i.e. FGM\&CIS recorded a peak in ion $\beta$ at 21:09 UT; a brief entry to PS observed by CIS and PEACE at 21:09 UT; an enhancement in energetic energy fluxes observed by RAPID 21:09 UT;

2nd substorm intensification

- Ground: A further negative deviation in $B_{x}$ at 21:15 UT; enhanced precipitation as observed by EISCAT at 21:14 UT;

- Cluster: FGM\&CIS recorded enhanced ion $\beta$ for $\sim 15$ min starting at 21:15 UT; PS entry observed by CIS and PEACE at 21:14 UT; 10-min enhancement starting at 21:15 UT in energetic energy fluxes observed by RAPID;

3rd substorm intensification

- Ground: A further negative deviation in $B_{x}$ at 21:51 UT; enhanced precipitation as observed by EISCAT at 21:48 UT;

- Cluster: Graze of PS observed by PEACE in s/c 2 at 21:50 UT; enhancement in energetic electron fluxes observed mainly by RAPID in s/c 2; signatures of a TCR passage (6th in Fig. 12) at 21:55 UT observed by FGM;

Start of recovery

- Ground: Decay of $B_{x}$ back to baseline, starting around 22:15 UT;

- Cluster: FGM\&CIS showed a rapid increase in ion $\beta$ starting at 22:15 UT; return to PS observed by CIS and PEACE at 22:15 UT; an increase of energetic electron fluxes to a slightly higher level just after 22:00 UT and a further intensification around 23:00 UT.

The Cluster spacecraft were located in the plasma sheet until the substorm activity started, after which they first left the plasma sheet and then moved in and out between the plasma sheet and the southern lobe. The motion of the plasma sheet-lobe boundary can be inferred by using all four spacecraft, and it often appears to also have significant Ycomponent, in addition to the Z-component. The measured boundary velocities are not high $(\lesssim 30 \mathrm{~km} / \mathrm{s})$ during the substorm, except during passing TCRs. The TCR observations suggest that several neutral lines are active during the substorm, with the main part of them forming tailward of Cluster and resulting in BBF-type TCRs.

At first glance the ground signatures of the substorm onset (as determined by magnetometers, the EISCAT radar in Troms $\varnothing$, and an all-sky camera in Kilpisjärvi) were detected a few minutes before Cluster observes the plasma sheet dropout. However, a closer examination reveals a slight density decrease of both ions and electrons in the tail, simultaneous with the ground signatures of the onset. This density decrease recovers before the plasma sheet dropout, but 


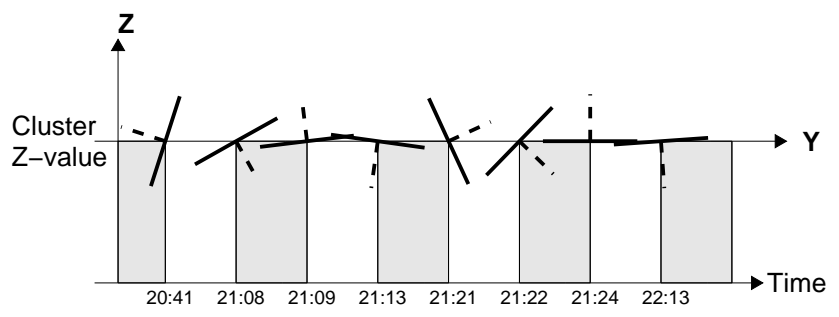

Fig. 16. YZ-plane of the plasma sheet boundary, shown as a fully drawn line, crossing the Cluster spacecraft constellation. The boundary normal is dashed, showing the direction in which the boundary moves past Cluster. Shaded areas indicate Cluster being inside the plasma sheet. Note that the time axis is not to scale. After 22:13 UT Cluster remains in the plasma sheet.

it is likely caused by activity in the central tail and therefore a result of the substorm onset. This, however, would mean that the onset is virtually simultaneous at the ground and at Cluster. For this event Cluster is probably displaced in the $\mathrm{Y}_{g s m}$-direction from the channel of activity in the central plasma sheet, and therefore we expect that some pre-onset (e.g. fast flows) and onset (e.g. field dipolarisations) signatures might be missed or delayed at Cluster, assuming information spreads toward the flanks as well as earthward.

\section{Discussion}

The Cluster spacecraft constellation has been designed with the intention to make observations of space plasma boundaries and has managed well regarding studies of, for example, the cusp, flux transfer events and TCRs (see, e.g. Special Issue, Cluster - First Results of Annales Geophysicae 19, 2001). However, for processes on the magnetospheric scale size the Cluster spacecraft separation cannot resolve the large-scale magnetotail dynamics, but instead provides more of a single-point measurement. This is the case during the event we have presented in this paper, where Cluster observes a number of plasma sheet boundary crossings in the magnetotail. Relying on data from Cluster alone would not provide a full picture of the cause for these boundary crossings, however, with the help of ground-based instruments we are able to put the tail observations into context, and determine that the magnetotail dynamics during this event are caused by a substorm, and more specifically, they are associated with the tail processes enhancing auroral precipitation and consequent electrojet intensifications.

Magnetotail dynamics can be solar wind-driven or caused by internal, for example, substorm-related, re-configuration. Here, the high correlation between substorm signatures on the ground and in the tail supports the connection with an internal substorm process. The correlation between signatures from the northern ground-hemisphere and the southern plasma sheet-lobe hemisphere also support the idea of interhemispheric symmetry in the substorm process. The substorm presented here is small, judging by the size of the ground magnetic perturbations. However, according to Dandouras et al. (1986), even weak substorms (defined by small AE) can lead to large perturbations of the plasma sheet, since according to their study, the amount of flux dropouts does not vary with $A E$.

Cluster observed a dropout from the plasma sheet into the lobe close to substorm onset, which at first glance could be interpreted as plasma sheet thinning. There are however several possible explanations to plasma sheet dropouts at substorm onset:

- Thinning of the plasma sheet, which is usually considered to be a process operating in the Z-direction. Recent papers (see references in Introduction) have argued against thinning at substorm onset, since it is hard to visualize why the behavior in the far tail should be opposite to that in the central near-tail region. There, observations show field dipolarisation and thickening of the plasma sheet at onset.

- Flapping of the whole tail, possibly in both the $\mathrm{Y}$ and Z-direction. Typical magnetotail flapping velocities and amplitudes vary with the downtail distance, according to Sergeev et al. (1998). They found that at a downtail distance of $20 R_{E}$, the typical flapping velocity was $100 \mathrm{~km} / \mathrm{s}$ and the amplitude $2 R_{E}$. At a downtail distance of $11 R_{E}$, the flapping velocity and amplitude were $10-20 \mathrm{~km} / \mathrm{s}$ and $0.2 R_{E}$, respectively. For some cases where plasma sheet dropouts have been observed at onset it has been suggested that the plasma sheet thickens at onset, but is moved away from the spacecraft, such that the thickening cannot be observed.

- Waves on the boundary between the PSBL and the lobe. Usually this boundary is considered as a smooth border, however, it is conceivable that this is not the case, particularly during times of substorm activity. Waves or large-scale disturbances could affect the appearance of the border locally (here "locally" implies a scale of at least the Cluster s/c separation).

In our case we can infer substantial boundary movement in both the Y- and Z-directions as Cluster moves between the different magnetotail regions. In Fig. 16 we visualize the boundary crossings in the YZ-plane, with time increasing towards the right (note that the time axis is not to scale). The boundary is fully drawn, and the boundary normal, showing the direction of movement, is dashed. The periods when Cluster is in the plasma sheet, as opposed to the lobe, are shown shaded with approximate times of entry/exit displayed under the time line. As can be seen in the figure, the Ycomponent had a non-negligiable influence at several boundary crossings. At the onset-associated plasma sheet dropout the boundary moved essentially in the dawnward direction. Thus, the dropout could not have been due to plasma sheet thinning in the Z-direction alone. (The process of thinning and thickening of the plasma sheet would be shown in the figure as a more or less horizontal boundary and vertical movement.) 
In this context it is important to remember that there may be some uncertainty in the mapping of the Cluster footpoint location. If the real footpoint was somewhat more east than T96 suggests (cf. Fig. 1) and the onset took place at the meridian of MIRACLE then Cluster was in the first place on the dawnward side of the onset region. One candidate to cause longitudinal error in the mapping are field-aligned currents that can change the magnetic field topology in a way that T96 cannot accomplish. The CUTLASS observation of the patch of enhanced equatorward flow at onset and at a location westward of the Cluster footpoint location seems to support this suggestion (cf. Fig. 9). Then if the onset region were associated with localized thinning Cluster would observe a dropout as a dawnward motion of the border of the longitudinally expanding onset region. This situation is described with the schematic drawings in Fig. 17. Whether the thinning covered the entire onset region (Nishida and Fuji, 1976; Hones et al., 1984) or appeared only at its flanks (Lyons and Huang, 1992, 1994) is difficult to say from our observations, since boundary orientations and motions after the first dropout imply very dynamic conditions (e.g. the TCR at 21:08-21:09 UT) within the onset sector.

The variations in the boundary normal direction around 21:20 UT in Fig. 16 resemble the corresponding variations deduced from Cluster data in the case study of a small substorm by Sergeev et al. (2003). In that case the flapping motion had vertical speeds exceeding $100 \mathrm{~km} / \mathrm{s}$ and the minimun variance analysis reveals that the current sheet was significantly tilted in the $\mathrm{Y}-\mathrm{Z}$ direction (cf. the drawings in the second row of Fig. 17). A similar configuration could also explain the observations of our event but confirming this is difficult as Cluster was not close enough to the current sheet and thus did not observe its crossings like in the event of Sergeev et al. Furthermore, in our case there were no obvious changes in the solar wind to trigger the flapping in the magnetotail while in the case of Sergeev et al. the solar wind pressure drop may have had this role.

Current sheet oscillations of internal origin are analysed in a more recent study by Sergeev et al. (2004). Their statistical study shows a clear tendency for the waves to propagate from the tail center towards flanks. This interpretation scheme resembles the picture of a longitudinally expanding onset region suggested in previous studies (Pulkkinen et al., 1995) and in this paper (cf. the drawings in the first row of Fig. 17), although relating the wavefront directly with the onset region boundary may not be justified without further observational evidence.

Admittedly, there are difficulties in determining with certainty the cause for the plasma sheet dropouts during a substorm, unless there is a suitably placed spacecraft in the opposite hemisphere, as in a recent Cluster-Geotail study by Nakamura et al. (2004). However, until a theory describing the cause for internally driven (i.e. not solar wind-driven) magnetotail flapping is presented, we suggest that plasma sheet thinning and thickening is intuitively a more plausible explanation to the observations made during this event.
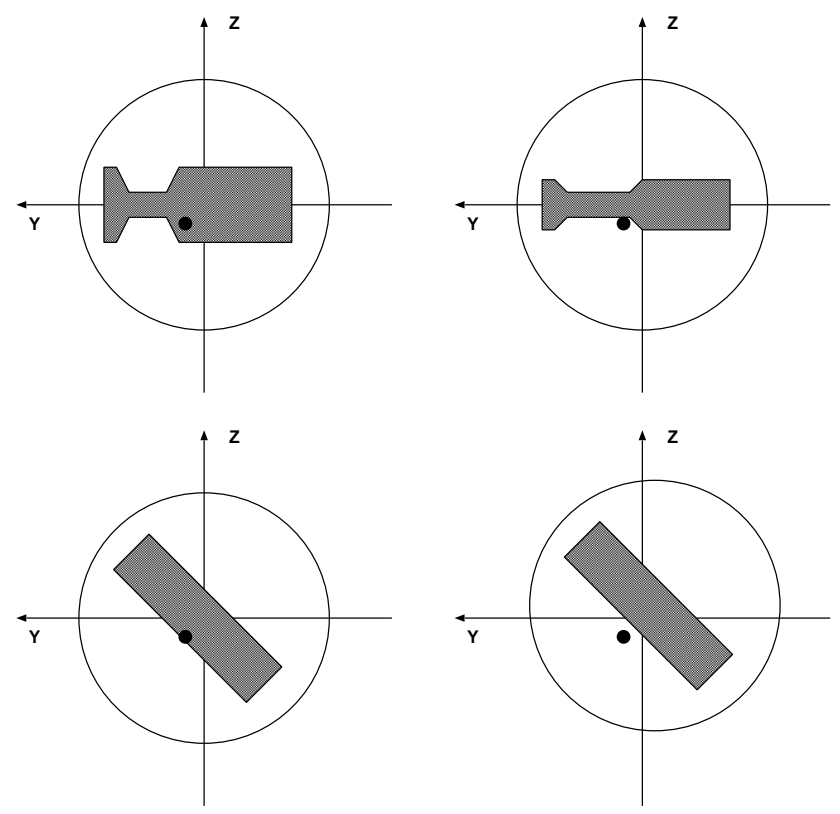

Fig. 17. Schematic tail cross-section showing how Cluster, marked by the black dot, initially inside the plasma sheet (left drawing), experiences plasma sheet drop-out as the thin onset region expands towards dawn (right drawing). The drawings in the second row show the effect of flapping of the entire tail with a tilted plasma sheet.

\section{Conclusions}

In this paper we have shown a case study of good correlation between substorm signatures on the ground and in the magnetotail. The fact that we see substorm features in the tail for this weak substorm means that even low-intensity substorms have an affect on a magnetospheric level.

We found that plasma sheet dynamics seem to be internally driven during this substorm, and the plasma sheet boundary motion can be as important in the Y-direction as in the Z-direction for the substorm onset and intensifications. We suggested that an azimuthally localized but expanding region of plasma sheet thinning would explain the observations of the boundary crossings with a significant Y-component in the motion. The question of plasma sheet dynamics during substorms should be investigated further, and Cluster, in combination with ground-based instruments and other spacecraft, has appeared to be an excellent tool for this purpose (Dewhurst et al., 2004) and the conditions for making statistical studies are also continuously improving as the data set grows.

Acknowledgements. We thank J. Baker (JHU/APL) and L. Rosenqvist (IRFU) for their support in reviving this study. We thank the institutes who maintain the IMAGE magnetometer array (the PI institute for IMAGE is the Finnish Meteorological Institute). EISCAT is an International Association supported by Finland (SA), France (CNRS), the Federal Republic of Germany (MPG), Japan (NIPR), Norway (NFR), Sweden (VR) and the United Kingdom (PPARC). Operation of the Northern Hemisphere SuperDARN radars is supported by the national funding agencies of the U.S., Canada, the UK, Japan, and France. We thank the PIs and data providers for 
Cluster. The PIs are; H. Rème (CIS), A. Fazakerley (PEACE), A. Balogh (FGM), and B. Wilken (RAPID). The Cluster coordinates for Fig. 1 and 3 were provided by SSCWeb. The data providers for WIND SWE are K. Ogilvie (NASA GSFC) and CDAWeb. We thank the WIND MFI team for supplying the magnetic field data. During part of the preparation of this manuscript, ML was supported by the Institute for Advanced Study, La Trobe University, Melbourne.

Editor in Chief thanks two referees for their help in evaluating this paper.

\section{References}

Akasofu, S.-I. and Meng, C.-I.: A study of polar magnetic substorms, J. Geophys. Res., 74, 293-313, 1969.

Akasofu, S.-I.: The solar wind - magnetosphere energy coupling and magnetospheric disturbances, Planet Space Sci., 28, 495$509,1980$.

Angelopoulos, V., Baumjohann, W., Kennel, C. F., Coroniti, F. V., Kivelson, M. G., Pellat, R., Walker, R. J., Lühr, H., and Paschmann, G.: Bursty bulk flows in the inner central plasma sheet, J. Geophys. Res., 97(A4), 4027-4039, 1992.

Balogh, A., Carr, C. M., Acuña, M. H., et al.: The Cluster magnetic field investigation: overview of in-flight performance and initial results, Ann. Geophys., 19, 1207-1217, 2001,

SRef-ID: 1432-0576/ag/2001-19-1207.

Bame, S. J., Ashbridge, J. R., Felthauser, H. E., Hones, E. W., and Strongy, I. B.: Characteristics of the plasma sheet in the Earth's magnetotail, J. Geophys. Res., 72, 113-129, 1967.

Baumjohann, W., Paschmann, G., and Cattell, C. A.: Average plasma properties in the central plasma sheet, J. Geophys. Res., 94, A6, 6597-6606, 1989.

Baumjohann, W., Paschmann, G., and Lühr, H.: Characteristics of high-speed ion flows in the plasma sheet, J. Geophys. Res., 95, 3801-3809, 1990.

Baumjohann, W., Paschmann, G., Nagai, T., and Lühr, H.: Superposed epoch analysis of the substorm plasma sheet, J. Geophys. Res., 96(A7), 11 605-11 608, 1991.

Baumjohann, W., Paschmann, G., and Nagai, T.: Thinning and expansion of the substorm plasma sheet, J. Geophys. Res., 97(A11), 17 173-17 175, 1992.

Belian, R. D., Gisler, G. R., Cayton, T., and Christensen, R. : High Z energetic particles at geosynchronous orbit during the great solar proton event of October, 1989, J. Geophys. Res., 97, 1689716906, 1992.

Chisham, G., Freeman, M. P., and Sotirelis, T.: A statistical comparison of SuperDARN spectral width boundaries and DMSP particle precipitation boundaries in the nightside ionosphere, Geophys. Res. Lett., 31, doi:10.1029/2003GL019074, 2004.

Cummings, W. D., Barfield, J. N. and Coleman, P. J.: Magnetospheric substorms observed at the geosynchronous orbit, J. Geophys. Res., 73, 6687-6698, 1968.

Dandouras, J., Reme, H., Saint-Marc, A., Sauvaud, J. A., Parks, G. K., Anderson, K. A. and Lin, R. P. : A statistical study of plasma sheet dynamics using ISEE 1 and 2 energetic particle flux data, J. Geophys. Res., 91(A6), 6861-6870, 1986.

Dewhurst, J. P., Owen, C. J., Fazakerley, A. N., and Balogh, A.: Thinning and Expansion of the Substorm Plasma Sheet, Ann. Geophys., 22, 4165-4184, 2004,

SRef-ID: 1432-0576/ag/2004-22-4165.

Escoubet, C. P., Fehringer, M., and Goldstein, M.: The Cluster mission, Ann. Geophys., 19, 1197-1200, 2001,
SRef-ID: 1432-0576/ag/2001-19-1197.

Greenwald, R. A., Baker, K. B., Dudeney, J. R., et al.: DARN/SuperDARN: A global view of the dynamics of highlatitude convection, Space Sci. Rev., 71, 761-796, 1995.

Harvey, C. C.: Spatial gradients and the volumetric tensor, in Analysis Methods for Multi-Spacecraft Data, ed. Paschmann, G., and Daly, P. W., ISSI Scientific Report SR-001, 1998.

Higbie, P. R., Belian, R. D., and Baker, D. N.: High-resolution energetic particle measurements at $6.6 R_{E} 1$, Electron micropulsations, J. Geophys. Res., 83, 4851-4855, 1978.

Hones, E. W., Pytte, T., and West, H. I. : Associations of geomagnetic activity with plasma sheet thinning and expansion: A statistical study, J. Geophys. Res., 89(A7), 5471-5478, 1984.

Johnstone, A. D., Alsop, C., Burge, S., et al.: PEACE: A Plasma Electron And Current Experiment, Space Sci. Rev., 79, 351-398, 1997.

Lepping, R. P., Acuña, M. Burlaga, L. Farrell, W., Slavin, J., Schatten, K., Mariani, F., Ness, N., Neubauer, F., Whang, Y. C., Byrnes, J., Kennon, R., Panetta, P., Scheifele, J., and Worley, E.: The WIND Magnetic Field Investigation, Space Sci. Rev., 71, 207-229, 1995.

Lester, M., Milan, S. E., Besser, V., and Smith, R.: A case study of HF radar backscatter and $630.0 \mathrm{~nm}$ auroral emission, Ann. Geophys., 19, 327-340, 2001,

SRef-ID: 1432-0576/ag/2001-19-327.

Liou, K., Meng, C.-I., Lui, A. T. Y., Newell, P. T., Brittnacher, M., Parks, G., and Nosé, M.: A fresh look at substorm onset indentifiers, in: Proceedings of the Fourth International Conference on Substorms, edited by: Kokobun, S. and Kamide, Y., 249-252, 1998.

Lyons, L. R. and Huang, C. Y.: Observations of plasma sheet expansion at substorm onset, $\mathrm{R}=15$ to $22 R_{E}$, Geophys. Res. Lett., 19, 1807-1810, 1992.

Lyons, L. R. and Huang, C. Y. : Plasma sheet expansion at $\mathrm{r}=15-$ $22 R_{E}$ : A recovery phase or expansion phase phenomenon?, J. Geophys. Res., 99(A6), 10 995-11 004, 1994.

Meng, C.-I. and Akasofu, S.-I. : A study of polar magnetic substorms: 2. Three-dimensional current system, J. Geophys. Res., 74, 4035-4053, 1969.

Miyashita, Y., Machida, S., Nishida, A., Mukai, T., Saito, Y., and Kokubun, S.: GEOTAIL observations of total pressure and electric field variations in the near and mid-distant tail associated with substorm onsets, Geophys. Res. Lett., 26, 639-642, 1999.

Nagai, T., Fujimoto, M., Saito, Y., Machita, S., Terasawa, T., Nakamura, R., Yamamoto, T., Mukai, T., Nishida, A., and Kokubun, S.: Structure and dynamics of magnetic reconnection for substorm onsets with Geotail observations, J. Geophys. Res., 103, 4419-4440, 1998.

Nakamura, R., Baumjohann, W., Noda, H., Torkar, K., Nagai, T., Fujimoto, M., Mukai, T., Klecker, B., Paschmann, G., PuhlQuinn, P.. Vaith, H., Bogdanova, J., Balogh, A., Rème, H., Sauvaud, J. A., Quinn, J., Torbert, R., and Kistler, L.: Plasma sheet expansion observed by Cluster and Geotail, in Frontiers in Magnetospheric Plasma Physics, 16, edited by: Hoshiro, M., Omura, Y., and Lanzerotti, L., 177-185, 2004.

Nishida, A. and Fuji, K.: Thinning of the near-Earth $\left(10-15 R_{E}\right)$ plasma sheet preceding the substorm expansion phase, Planet Space Sci., 24, 849-853, 1976.

Ogilvie, K. W., Chorney, D. J., Fitzenreiter, R. J., Hunsaker, F., Keller, J., Lobell, J., Miller, G., Scudder, J. D., Sittler Jr., E. C., Torbert, R. B., Bodet, D., Needell, G., Lazarus, A. J., Steinberg, J. T., Tappan, J. H., Mavretic, A., and Gergin E.: SWE, a com- 
prehensive plasma instrument for the WIND spacecraft, Space Sci. Rev, 71, 55-77, 1995.

Owen, C. J., Fazakerley, A. N., Carter, P. J., Coates, A. J., Krauklis, I. C., Szita, S., Taylor, M. G. G. T., Travnicek, P., Watson, G., Wilson, R. J., Balogh A., and Dunlop M. W.: CLUSTER PEACE observations of electrons during magnetospheric flux transfer events, Ann. Geophys., 19, 1509-1522, 2001,

SRef-ID: 1432-0576/ag/2001-19-1509.

Pulkkinen, T. I., Baker, D. N., Pellinen, R. J., Murphree, J. S., and Frank, L. A.: Mapping or the auroral oval and individual arcs during substorms, J. Geophys. Res., 100, 21 987-21 994, 1995.

Reeves, G. D.: New perspectives on substorm injections, Substorms-4, Proc. ICS-4, Hamanako, Japan, Kokubun, S. and Kamide Y. (Eds.), Kluwer Academic Publishers, Boston, 785790, 1998.

Rème, H., Aoustin, C., Bosqued, J. M., et al.: First multispacecraft ion measurements in and near the Earth's magnetosphere with the identical Cluster Ion Spectrometry (CIS) experiment, Ann. Geophys., 19, 1303-1354, 2001,

SRef-ID: 1432-0576/ag/2001-19-1303

Rishbeth, H. and Williams, P. J. S.: The EISCAT ionospheric radar: the system and its early results, Q. J1 R. Astr. Soc., 26, 478-512, 1985.

Ruohoniemi, J. M. and Baker, K. B. : Large-scale imaging if highlatitude convection with Super Dual Auroral Radar Network HF radar observations, J. Geophys. Res., 103(A9), 20 797-20811, 1998.

Russell, C. T., Snare, R. C., Means, J. D., Pierce, D. Dearborn, D., Larson, M., Barr, G., and Le, G.: The GGS/Polar magnetic fields investigation, Space Sci. Rev., 71, 563-582, 1995.

Sergeev, V., Angelopoulos, V., Carlson, C., and Sutcliffe, P.: Current sheet measurements within a flapping plasma sheet, J. Geophys. Res., 103(A5), 9177-9187, 1998.

Sergeev, V., Runov, A., Baumjohann, W., Nakamura, R., Zhang, T. L., Volwerk, M., Balogh, A., Reme, H., Sauvaud, J. A., Andre, M., and Klecker, B.: Current sheet flapping motion and structure observed by Cluster, Geophys. Res. Lett., 30, CiteID 1327, doi:10.1029/2002GL016500, 2003.

Sergeev, V., Runov, A., Baumjohann, W., Nakamura, R., Zhang, T. L., Balogh, A., Louarnd, P., Sauvaud, J.-A., and Réme, H.: Orientation and propagation of current sheet oscillations, Geophys. Res. Lett., 31, doi:10.1029/2003GL019346, 2004.

Shodhan, S., Siscoe, G. L., Frank, L. A., Ackerson, K. L., and Paterson, W. R. : Boundary oscillations at Geotail: Windsock, breathing, and wrenching, J. Geophys. Res., 101(A2), 25772586, 1996.

Siscoe, G. L., Frank, L. A., Ackerson, K. L., and Paterson, W. R.: Irregular long-period boundary oscillations beyond $100 \mathrm{Re}$ : Geotail plasma observations, Geophys. Res. Lett., 21, 2979-2982, 1994.

Slavin, J. A., Smith, E. J., Tsurutani, B. T., Sibeck, D. G., Singer, H. J., Baker, D. N., Gosling, J. T., Hones Jr., E. W., and Scarf, F. I.: Substorm-associated travelling compression regions in the distant tail: ISEE 3 geotail observations, Geophys. Res. Lett., 11, 657-660, 1984
Slavin, J. A., Smith, M. F., Mazur, E. L., Baker, D. N., Iyemori, T., and Greenstadt, E. W.: ISEE-3 observations of traveling compression regions in the Earth's magnetotail, J. Geophys. Res., 98, 15 425-15 446, 1993.

Slavin, J. A., Lepping, R. P., Gjerloev, J., Fairfield, D. H., Hesse, M., Owen, C. J., Moldwin, M. B., Nagai, T., Ieda, A., and Mukai, T.: Geotail observations of magnetic flux ropes in the plasma sheet, J. Geophys. Res., 108(A1), 1015, doi:10.1029/2002JA009557, 2003a.

Slavin, J. A., Lepping, R. P., Gjerloev, J., Goldstein, M. L., Fairfield, D. H., Acuña, M. H., Balogh, A., Dunlop, M., Kivelson, M. G., Khurana, K., Fazakerley, A., Owen, C. J., Réme, H., and Bosqued, J.-M.: Cluster electric current density measurements within a magnetic flux rope in the plasma sheet, Geophys. Res. Lett., 30(7), 14-1, CiteID 1362, doi:10.1029/2002GL016411, $2003 b$.

Slavin, J. A., Owen, C. J., Dunlop, M. W., Borälv, E., Moldwin, M. B., Sibeck, D. G., Tanskanen, E., Goldstein, M. L., Fazakerley, A., Balogh, A., Lucek, E., Richter, I., Réme, H., and Bosqued, J.-M.: Cluster four spacecraft measurements of small traveling compression regions in the near-tail, Geophys. Res. Lett., 30(23), SSC 7-1, CiteID 2208, doi:10.1029/2003GL018438, 2003c.

Slavin, J. A., Tanskanen, E., Hesse, M., Owen, C. J., Dunlop, M. W., Imber, S., Lucek, E. A., Balogh, A., and Glassmeier, K.H.: Cluster observations of traveling compression regions in the near-tail, J. Geophys. Res., in press , 2005.

Syrjäsuo, M. T., Pulkkinen, T. I., Janhunen, P., Viljanen, A., Pellinen, R. J., Kauristie, K., Opgenoorth, H. J., Wallman, S., Eglitis, P., Karlsson, P., Amm, O., Nielsen, E., and Thomas, C.: Observations of substorm electrodynamics using the MIRACLE network, SUBSTORMS-4, Kokobun, S., and Kamide, Y. (Eds.), Terra Scientific Publishing Company/Kluwer Academic Publishers, 111114, 1998.

Taguchi, S., Slavin, J. A., and Lepping, R. P.: Traveling compression regions in the mid-tail: 15 Years of IMP 8 observations, J. Geophys. Res., 103, 17 641-17 650, 1998.

Torkar, K., Riedler, W., Fehringer, M., Escoubet, C. P., Svenes, K., Narheim, B. T., Fazakerley, A. N., Szita, S., and André, M.: Effects of active spacecraft potential control on Cluster plasma observations - First results, Proceedings of the 7th Spacecraft Charging Technology Conference, ESA SP-476, 255, 2001.

Tsyganenko, N. A. and Stern, D. P.: Modeling the global magnetic field of the large-scale Birkeland current systems, J. Geophys. Res., 101, 27 187-27 198, 1996.

Viljanen, A. and Häkkinen, L.: IMAGE magnetometer network, in Satellite-ground based coordination sourcebook, edited by: Lockwood, M., Wild, M. N., and Opgenoorth, H. J., ESA publications SP-1198, 111-117, 1997.

Wilken, B., Daly, P. W., Mall, U., et al.: First results from the RAPID imaging energetic particle spectrometer on board Cluster, Ann. Geophys., 19, 1355-1366, 2001,

SRef-ID: 1432-0576/ag/2001-19-1355. 